\title{
CHEMOSPHERE
}

\section{Phototransformation of polychlorinated dibenzo- $p$-dioxins from photolysis of pentachlorophenol on soils surface}

\author{
Peng-Yan Liu ${ }^{\text {a,b }}$, Ming-Hui Zheng ${ }^{\text {a,* }}$, Xiao-Bai Xu ${ }^{\text {a }}$ \\ ${ }^{a}$ Research Center for Eco-Environmental Sciences, Chinese Academy of Sciences, P.O.Box 2871, Beijing 100085, China \\ b Department of Chemistry, Hebei University, Baoding 071002, China
}

Received 11 January 2001; received in revised form 26 August 2001; accepted 19 September 2001

\begin{abstract}
The phototransformation of polychlorinated dibenzo-p-dioxins (PCDDs) by photolysis of pentachlorophenol (PCP) on soil surface under irradiation of UV light in the laboratory has been investigated. Octachlorodibenzo- $p$-dioxin (OCDD) and heptachlorodibenzo- $p$-dioxin $\left(\mathrm{H}_{7} \mathrm{CDD}\right)$ were detected from the products of the photoreactions. The effects of soil types with different basic soil physicochemical properties were varied from silt loam, silt clay and clay soil on the formation of PCDDs by irradiation of PCP on soils surface. Fulvic acids can prevent phototransformation of PCDDs by photolysis of PCP on soil surface. (c) 2002 Elsevier Science Ltd. All rights reserved.
\end{abstract}

Keywords: Polychlorinated dibenzo-p-dioxins; Pentachlorophenol; Photolysis; Formation; Soil

\section{Introduction}

Polychlorinated dibenzo-p-dioxins (PCDDs) and dibenzofurans (PCDFs) are ubiquitous environmental contaminants. The occurrence of PCDDs in the environment originated from both natural and synthetic sources (Rappe, 1994).

Likewise, chlorophenols occur almost in every area of environment. Photoformation and photodegradation by sunlight are important processes for the turnover of environmental contaminants.

The photolytic condensation of chlorophenols has been widely studied (Piccinni et al., 1998). Irradiation of alkaline aqueous solution of pentachlorophenol (PCP) has been reported to produce octachlorodibenzo- $p$ dioxin (OCDD) (Crosby and Wong, 1976). It also has been proved that the irradiation of several PCPcontaining aqueous solutions indicated the formation of higher chlorinated PCDD/Fs (Vollmuth et al., 1994). Laboratory studies have been conducted to determine

\footnotetext{
*Corresponding author. Fax: +86-10-62943657.

E-mail address: zhengmh@mail.rcees.ac.cn (M.-H. Zheng).
}

the effect of sunlight on the concentrations of PCP and PCDDs in wood treated with PCP (Lamparski and Stehl, 1980). However, few studies on the phototransformation of PCDDs via photolysis of PCP on soils surface have been reported. The objective of this study was to investigate the effects of soil types with different basic soil physicochemical properties on the phototransformation of PCDDs by photolysis of PCP on soils surface.

\section{Experimental}

\subsection{Reagents and soil samples}

Triple distilled water (from $\mathrm{KMnO}_{4}$ and $\mathrm{K}_{2} \mathrm{Cr}_{2} \mathrm{O}_{7}$ ) was used. PCP, whose purity has been described by the manufacturer as $99 \%$, was purified as described to remove impurities of PCDD/Fs (Vollmuth et al., 1994). ${ }^{13} \mathrm{C}$-labelled 2,3,7,8-substituted $\mathrm{PCDD} / \mathrm{Fs}$ congeners were obtained from Cambridge Isotope Laboratories.

Silt loam and silt clay used for this study were collected from 0 to $30 \mathrm{~cm}$ depth increment at a range site in Beijing, and a clay soil was collected from 0 to $50 \mathrm{~cm}$ depth increment at a range site at Hangzhou in China. 
The physicochemical properties of the soil samples were presented in Table 1. There were no detectable background levels of PCP and PCDDs in the soils. The samples of soil were air-dried, homogenized, ground and sieved $(40-80 \mu \mathrm{m})$. Fortified soil samples were prepared by adding each standard solution of PCP in $n$-hexane to the samples to obtain $1 \mathrm{mg} \mathrm{PCP} / \mathrm{g}$ soil samples. After fortification, the samples were homogenized and kept at room temperature for $2 \mathrm{~h}$ to allow evaporation of the solvent.

\subsection{Irradiation experiments}

Photolysis experiments were conducted through exposing soil samples to UV light emitted by a $300 \mathrm{w}$ medium-pressure Hg-lamp. The photochemical apparatus (model NDC, Nanjing Changning Radio Plant, China) was shown in Fig. 1. The soil plates with a size of $5 \times 10 \mathrm{~cm}$ had a soil layer of $0.08 \mathrm{~mm}$ thickness.

\subsection{Analytical procedures}

After irradiating, soil samples were spiked with ${ }^{13} \mathrm{C}$ labeled PCDD/Fs and extracted three times with $15 \mathrm{ml}$ n-hexane/acetone (1:1) under sonication for $30 \mathrm{~min}$. Hundred milliliters $1 \% \mathrm{~K}_{2} \mathrm{CO}_{3}$ solution was added to the extracts. The organic and aqueous phases were pooled and then treated differently for the analyses of PCP and PCDDs. The remained PCP in alkaline aqueous layer was reacted with acetic anhydride and the derivatives were analyzed with a Hitachi 663-50 gas chromatography equipped with an ECD detector and a DB-5

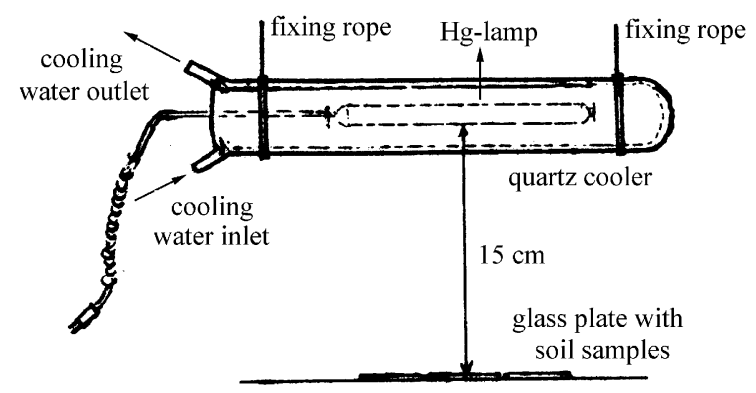

Fig. 1. Schematic experimental unit for the photolysis experiments. capillary column $(30 \mathrm{~m} \times 0.25 \mathrm{~mm}, \mathrm{~J} \& \mathrm{~W})$. The organic layer was washed with water and then concentrated to 1 $\mathrm{ml}$ by a rotavapor. The concentrated organic solution was clean up on a basic alumina column. Hexane/ dichloromethane (98:2) and hexane/dichloromethane (1:1) were used as eluant. The last eluate contained PCDD/Fs was concentrated to $0.2 \mathrm{ml}$. An Agilent 6890 GC/5973N MS was used for analyses of the PCDDs. The capillary column was an HP-5 MS (60 $\mathrm{m} \times$ $0.32 \mathrm{~mm}$, Agilent). Quantitative of PCDDs was performed in selected ion monitoring mode using two most abundant ion clusters.

\section{Results and discussion}

The kinetics of PCP disappearance on soil plates was shown in Fig. 2. The results of photodegradation of PCP were lower on clay soil than silt loam. This is primarily due to the fact that light attenuation was more obvious by clay loam than silt loam.

The detection limits for PCDD/Fs is $0.02 \mathrm{ng} / \mathrm{g}$ soil in this study. Many PCDD/F isomers were found in direct photolysis of chlorinated phenols in aqueous solution (Skurlatov et al., 1998), but only OCDD and heptachlorodibenzo-p-dioxin $\left(\mathrm{H}_{7} \mathrm{CDD}\right)$ were detected in this study. The amount of $\mathrm{H}_{7} \mathrm{CDD}$ was only about $1 \%$ of OCDD. Phototransformation of PCDDs by photolysis of PCP on soils surface was shown in Fig. 3.

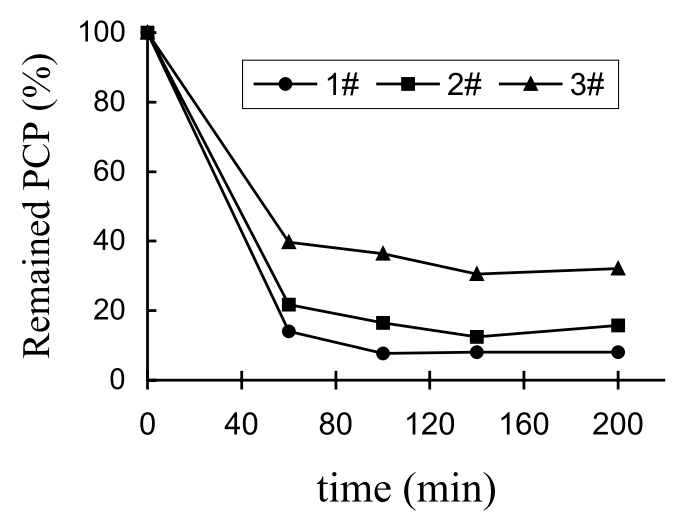

Fig. 2. Kinetic of PCP disappearance upon irradiation of PCP on soil surface.

Table 1

The characteristics of soils used in photolysis experiments

\begin{tabular}{lllllllll}
\hline Soil & No. & Density $\left(\mathrm{g} / \mathrm{cm}^{3}\right)$ & Sand $(\%)$ & Silt $(\%)$ & Clay $(\%)$ & Organic C $(\%)$ & pH & Humic acid $(\%)$ \\
\hline Silt loam & $1 \#$ & 2.62 & 51.0 & 27.3 & 12.7 & 0.344 & 7.68 & 0.067 \\
Silt clay & $2 \#$ & 2.49 & 11.3 & 47.5 & 41.2 & 0.198 & 7.69 & 0.151 \\
Clay soil & $3 \#$ & 2.41 & 12.1 & 38.7 & 49.2 & 0.827 & 4.43 & 0.481 \\
\hline
\end{tabular}




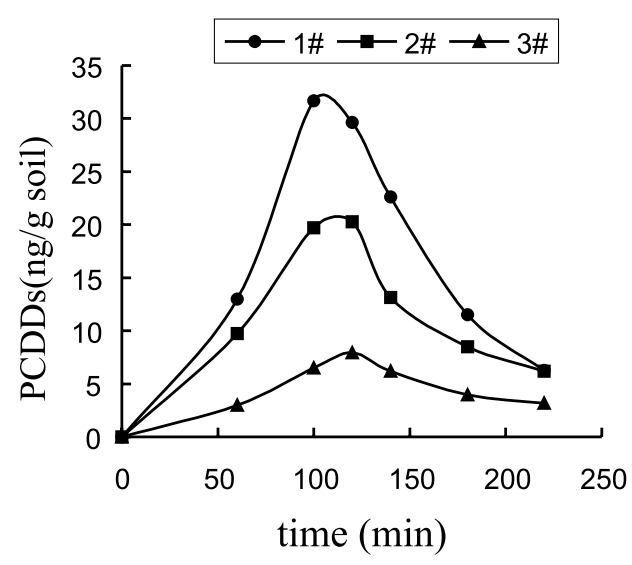

Fig. 3. Phototransformation of PCDDs by photolysis of PCP on soils surface (the amount of PCDDs was actually the total amount of $\mathrm{OCDD}$ and $\mathrm{H}_{7} \mathrm{CDD}$ ).

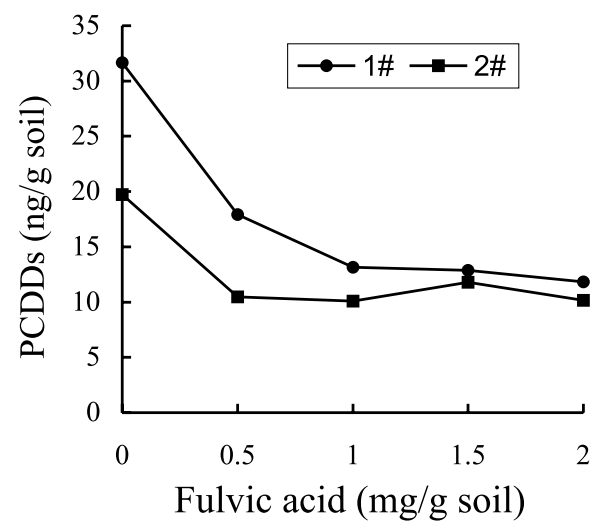

Fig. 4. Influence of fulvic acid on phototransformation of PCDDs (the amount of PCDDs was actually the total amount of $\mathrm{OCDD}$ and $\left.\mathrm{H}_{7} \mathrm{CDD}\right)$.

Fulvic acids can prevent formation of PCDD/Fs by photolysis of chlorinated phenols in aqueous solution, possibly as a result of trapping of intermediate radicals (Skurlatov et al., 1998). The same phenomenon was observed in photolysis of PCP on soil surface (Fig. 4).

The influence of $\mathrm{pH}$ of soils on the phototransformation of PCDDs has been studied. The solution of
Table 2

Influence of $\mathrm{pH}$ on the formation of PCDDs (irradiation time: $100 \mathrm{~min}, \mathrm{ng} / \mathrm{g}$ soil)

\begin{tabular}{llll}
\hline Soil & $\mathrm{pH} 4.4$ & $\mathrm{pH} \mathrm{7.6}$ & $\mathrm{pH} \mathrm{9.6}$ \\
\hline $1 \#$ & 31.75 & 31.67 & 26.74 \\
$2 \#$ & 14.37 & 19.72 & 18.31 \\
$3 \#$ & 7.81 & 10.65 & 16.91 \\
\hline
\end{tabular}

$\mathrm{NaOH}$ or $\mathrm{H}_{2} \mathrm{SO}_{4}$ was added to the soil samples before irradiation to obtain different values of $\mathrm{pH}$. The value of $\mathrm{pH}$ affected greatly on the phototransformation of PCDDs when irradiation of soil samples (Table 2). The effects of $\mathrm{pH}$ were varied from different types of soil on formation of PCDDs.

\section{Acknowledgements}

This study was supported by Chinese Academy of Sciences (Grant No. KZ951-B1-209-03). The authors are grateful to Agilent Tech. Co. in China for the apparatus support.

\section{References}

Crosby, D.G., Wong, A.S., 1976. Photochemical generation of chlorinated dioxin. Chemosphere 5, 327-332.

Lamparski, L.L., Stehl, R.H., 1980. Photolysis of pentachlorophenol-treated wood: chlorinated dibenzo-dioxin formation. Environ. Sci. Technol. 14, 196-200.

Piccinni, P., Pichat, P., Guilard, C., 1998. Phototransformations of soild pentachlorophenol. J. Photochem. Photobiol. A: Chem. 119, 137-142.

Rappe, C., 1994. Dioxin patterns and source identification. Fresenius. J. Anal. Chem. 384, 63-75.

Skurlatov, Y.I., Ernestova, L.S., Vichutinskaya, E.V., Samsonov, D.P., et al., 1998. Formation of dibenzodioxins and dibenzofurans in the photochemical transformation of polychlorinated phenols. Acta Hydrochim. Hydrobiol. 26, 31-35.

Vollmuth, S., Zajic, A., Niessner, R., 1994. Formation of polychlorined dibenzo- $p$-dioxins and polychlorinated dibenzofurans during the photolysis of pentachlorophenolcontaining water. Environ. Sci. Technol. 28, 1145-1149. 